\title{
Process-Induced Deformation of Composite T-Stiffener Structures
}

\author{
Chensong Dong* \\ Department of Mechanical Engineering \\ Curtin University of Technology \\ GPO Box 1987, Perth, WA 6845, Australia
}

\begin{abstract}
Composite T-stiffener structures are widely used structural elements in weight sensitive structural, aerospace and marine applications for the purpose of weight reduction. A study on the process-induced deformation of composite T-stiffener structures is presented in this paper. The deformation was calculated numerically by Finite Element Analysis (FEA), and the resulting displacements show that the deformation can be represented by a single angular displacement: the spring-in of the skin. A parametric study was conducted by Design of Experiments (DOE) and FEA to investigate the influence of design parameters on the springin of the skin. It is shown that the spring-in of the skin increases with the radius and the bonding length, and decreases with the fiber volume fraction.
\end{abstract}

Keywords: Composite; T-stiffener; deformation

\section{Introduction}

Composites offer the advantages of low density, high strength, high stiffness to weight ratio, excellent durability, and design flexibility. Composite T-stiffener structures are widely used

\footnotetext{
* Tel.: +61 (8) 92669204; fax: +61 (8) 92662681; email: c.dong@curtin.edu.au
} 
structural elements in weight sensitive structural, aerospace and marine applications for the purpose of weight reduction. They are often called integrated structures because the parts connected by the fasteners are replaced by molded parts. These integrated structures are often made of flat or curved panels with co-cured or adhesively bonded frames and stiffeners. T-stiffener composite structures can be made by the prepreg/autoclave or the resin transfer molding (RTM) process. The prepreg/autoclave process can be further categorized into three different processing methods: co-curing, co-bonding and secondary bonding [1]. When the RTM process is used, the whole part is molded as one piece or the spar and skin are molded separately and bonded together with an adhesive [2].

Anisotropy, the main characteristic of composite materials, is an advantage from the perspective of structural design, but is also a main cause of process-induced deformation. Past research on the process-induced deformation of composites was mainly focused on the spring-in of angled parts i.e. the reduction in the enclosed angle. The spring-in of composites was either studied by elastic or viscoelastic models. When the elastic models were used, both analytical and numerical methods were developed. Hahn and Pagano [3] performed an elastic analysis of the residual stresses in a thermoset matrix composite. Radford and Diefendorf [4] developed a simple mathematical formula to predict the spring-in of curved shaped parts, which was used by Huang and Yang [5] in their experimental studies. Kollar [6] presented an approximate analysis of spring-in. Jain and Mai [7, 8] developed a mechanicsbased model using modified shell theory. For a more complex shape e.g. T-stiffener, numerical methods are often needed. Wang et al. [9] conducted a finite element analysis of spring-in using ABAQUS. Ding et al. [10] developed a 3-D finite element analysis procedure to predict spring-in resulting from anisotropy for both thin and thick angled composite shell structures.

The mechanical behavior of composite materials is better represented by a viscoelastic model. 
Some studies calculated the residual stress developed during the cooling down stage by thermo-viscoelastic models [11-13]. Others [14-20] also addressed the residual stresses developed before cooldown, i.e. during the curing process. White and Hahn [14, 15] studied the residual stress development during the curing of thin laminates by a 2-D finite difference thermo-chemical model and a generalized plane-strain finite element model. Li et al. [16] used a plane-strain, linearly elastic finite element model with temperature-dependent matrix properties to analyze the evolution of residual stresses in graphite-PEEK composites during curing. Wiersma et al. [17] developed a thermo-elastic model and extended it into a thermoviscoelastic model. A plane-strain finite element process model COMPRO was developed to simulate the spring-in and warpage in the autoclave process [18, 19]. Zhu et al. [20] developed a fully 3-D coupled thermo-chemo-viscoelastic finite element model to simulate the heat transfer, curing, and residual stress development during the manufacturing cycle of thermoset composite parts.

From the literature, it can be seen that although the process induced deformation of composites such as spring-in was studied either analytically or numerically, the deformation of T-stiffener structures has not received much attention. Both elastic and viscoelastic models were developed for calculating the process-induced deformation of composites. Compared with elastic models, viscoelastic models are more complicated to use. During the curing process, approximately $60 \%$ of the total shrinkage occurs prior to the gel point [21]. In addition, after demolding, the composite is usually post-cured at an elevated temperature above the glass transition temperature $T_{g}$. During this process, the stresses induced by curing can be significantly relaxed [22-24]. Thus, only a small fraction of curing shrinkage contributes to the residual stress and warpage development. For this reason, an elastic approach was employed in this study. The deformation was computed by FEA, and the resulting displacements show that the deformation can be represented by a single angular 
displacement: the spring-in of the skin. A parametric study was conducted by Design of Experiments and FEA to investigate the influence of design parameters on the spring-in of the skin. The paper is organized as follows: Section 2 presents the modeling of deformation; the deformation is characterized in Section 3; the parametric study is presented in Section 4 and finally the conclusions are given in Section 5.

\section{Deformation Modeling}

\subsection{Governing equations}

In order to model the deformation, the material properties of composites need to be derived. A composite part normally consists of a number of laminas stacked in a certain sequence. The orientation of an individual lamina is represented by $\theta$, as shown in Figure 1.

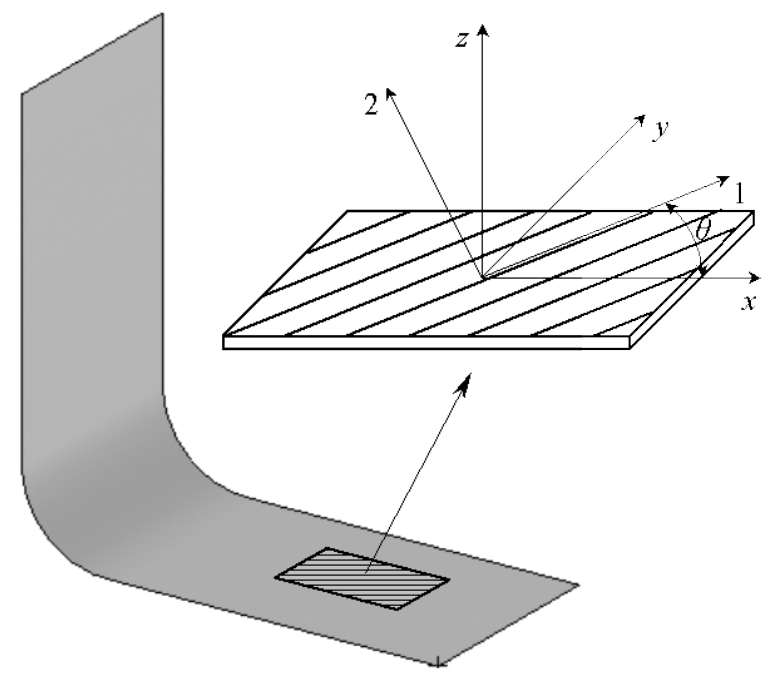

Figure 1: Definition of principal material axes and loading axes for a lamina

In the global coordinate system, the stress-strain relationship is given by the constitutive law for a monotropic material [25], i.e. 


$$
\left[\begin{array}{cccccc}
\bar{C}_{11} & \bar{C}_{12} & \bar{C}_{13} & 0 & 0 & \bar{C}_{16} \\
\bar{C}_{12} & \bar{C}_{22} & \bar{C}_{23} & 0 & 0 & \bar{C}_{26} \\
\bar{C}_{13} & \bar{C}_{23} & \bar{C}_{33} & 0 & 0 & \bar{C}_{36} \\
0 & 0 & 0 & \bar{C}_{44} & \bar{C}_{45} & 0 \\
0 & 0 & 0 & \bar{C}_{45} & \bar{C}_{55} & 0 \\
\bar{C}_{16} & \bar{C}_{26} & \bar{C}_{36} & 0 & 0 & \bar{C}_{66}
\end{array}\right]\left[\begin{array}{c}
\varepsilon_{x x}-\alpha_{x x} \Delta T \\
\varepsilon_{y y}-\alpha_{y y} \Delta T \\
\varepsilon_{z z}-\alpha_{z z} \Delta T \\
\gamma_{y z} \\
\gamma_{x z} \\
\gamma_{x y}-2 \alpha_{x y} \Delta T
\end{array}\right]=\left[\begin{array}{c}
\sigma_{x x} \\
\sigma_{y y} \\
\sigma_{z z} \\
\tau_{y z} \\
\tau_{x z} \\
\tau_{x y}
\end{array}\right]
$$

where $\left[\bar{C}_{i j}\right]$ is the stiffness matrix; $\varepsilon_{x x}, \varepsilon_{y y}, \varepsilon_{z z}, \gamma_{y z}, \gamma_{x z}$, and $\gamma_{x y}$ are the strain; $\alpha_{x x}, \alpha_{y y}, \alpha_{z z}$, and $\alpha_{x y}$ are the CTE; $\Delta T$ is the temperature difference; and $\sigma_{x x}, \sigma_{y y}, \sigma_{z z}, \tau_{y z}, \tau_{x z}$, and $\tau_{x y}$ are the stress. In order to calculate the deformation, the stiffness matrix and CTE need be derived from the lamina properties.

\subsection{Lamina properties}

The effective lamina properties of composites are dependent on the constituent properties and fiber volume fraction $V_{f}$. Generally, the properties of fibers are independent of temperature. As for resins, the CTE and Poisson's ratio is constant below $T_{g}$ while the elastic modulus is temperature-dependent. The mechanical properties of an epoxy resin from DMA (Dynamic Mechanical Analysis) are as shown in Figure 2, from which it is shown that the modulus decreases approximately linearly from the room temperature to $T_{g}$.

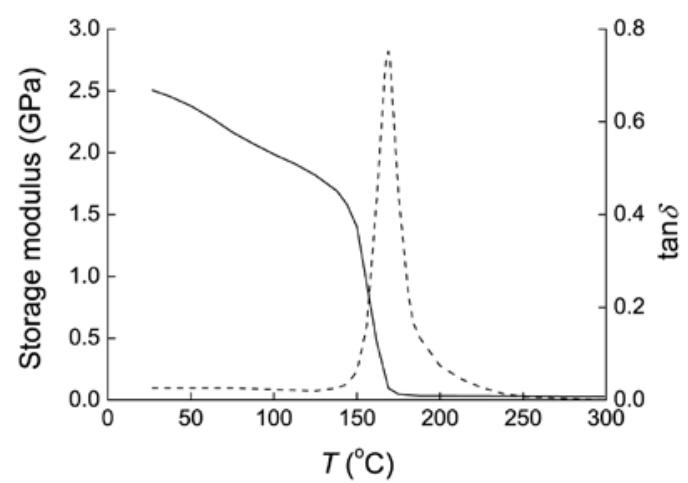


In this study, the materials are assumed to be AS4 graphite fibers and epoxy resin. Their properties and CTE are shown in Table 1.

Table 1: Material properties of AS4 fiber and epoxy resin [26]

\begin{tabular}{|c|c|c|c|c|c|c|c|c|}
\hline \multirow[t]{2}{*}{ AS4 fibres } & $\begin{array}{c}E_{f L} \\
(\mathbf{G P a})\end{array}$ & $\begin{array}{c}E_{f T} \\
(\mathbf{G P a})\end{array}$ & $\begin{array}{c}G_{f} \\
(\mathbf{G P a})\end{array}$ & $\begin{array}{c}G_{f T T} \\
(\mathrm{GPa})\end{array}$ & $v_{f}$ & $v_{f T T}$ & $\begin{array}{c}\alpha_{f L} \\
\left(10^{-6} /{ }^{\circ} \mathrm{C}\right)\end{array}$ & $\begin{array}{c}\alpha_{f T} \\
\left(10^{-6} /{ }^{\circ} \mathrm{C}\right)\end{array}$ \\
\hline & 235 & 14 & 6.917 & 5 & 0.2 & 0.4 & -0.4 & 18 \\
\hline \multirow[t]{2}{*}{ Epoxy } & \multicolumn{2}{|c|}{$\begin{array}{c}E_{m} \text { at } 20^{\circ} \mathrm{C} \\
\text { (GPa) }\end{array}$} & \multicolumn{2}{|c|}{$\begin{array}{c}E_{m} \text { at } 150^{\circ} \mathrm{C} \\
(\mathrm{GPa})\end{array}$} & \multicolumn{2}{|c|}{$v_{m}$} & \multicolumn{2}{|c|}{$\alpha_{m}\left(10^{-6} /{ }^{\circ} \mathrm{C}\right)$} \\
\hline & \multicolumn{2}{|c|}{2.581} & \multicolumn{2}{|c|}{1.620} & \multicolumn{2}{|c|}{0.265} & \multicolumn{2}{|c|}{64} \\
\hline
\end{tabular}

Based on these constituent properties, the lamina properties, including the longitudinal modulus $E_{11}$, the transverse modulus $E_{22}$ or $E_{33}$, and the shear moduli $G_{12}, G_{13}$, and $G_{23}$, are derived by Hashin's model [25] for two temperatures $20^{\circ} \mathrm{C}$ and $150^{\circ} \mathrm{C}$, respectively. These lamina properties are used to derive the stiffness matrix $\overline{\mathbf{C}}$. At any temperature $T$ between $20^{\circ} \mathrm{C}$ and $150^{\circ} \mathrm{C}, \bar{C}_{i j}$ is given by

$$
\bar{C}_{i j, T}=\frac{\bar{C}_{i j, 20}(150-T)+\bar{C}_{i j, 150}(T-20)}{130}
$$

\subsection{Coefficient of thermal expansion}

The longitudinal CTE of the lamina is given by

$$
\alpha_{11}=\frac{\alpha_{f L} E_{f L} V_{f}+\alpha_{m} E_{m}\left(1-V_{f}\right)}{E_{f L} V_{f}+E_{m}\left(1-V_{f}\right)}
$$

where $\alpha_{f L}$ is the longitudinal CTE of fiber; $\alpha_{m}$ is the CTE of resin; $E_{f L}$ is the longitudinal modulus of fiber; and $E_{m}$ is the modulus of resin.

The transverse CTE of the lamina is calculated by Hashin's concentric cylinder model [27]. 


$$
\begin{aligned}
\alpha_{22} & =\hat{\alpha}_{22}+\left(\bar{S}_{12}-\hat{S}_{12}\right)\left[\left(\alpha_{f L}-\alpha_{m}\right) P_{11}+2\left(\alpha_{f T}-\alpha_{m}\right) P_{12}\right] \\
& +\left(\bar{S}_{22}-\hat{S}_{22}\right)\left[\left(\alpha_{f L}-\alpha_{m}\right) P_{12}+\left(\alpha_{f T}-\alpha_{m}\right)\left(P_{22}+P_{23}\right)\right] \\
& +\left(\bar{S}_{23}-\hat{S}_{23}\right)\left[\left(\alpha_{f L}-\alpha_{m}\right) P_{12}+\left(\alpha_{f T}-\alpha_{m}\right)\left(P_{22}+P_{23}\right)\right]
\end{aligned}
$$

where $\bar{S}_{i j}$ and $\hat{S}_{i j}$ are the effective and average composite compliance; $\alpha_{f T}$ is the transverse CTE of fiber; and $P_{i j}$ is given by

$$
\begin{aligned}
& P_{11}=\left(A_{22}^{2}-A_{23}^{2}\right) / \operatorname{det} \mathbf{A} \\
& P_{12}=\left(A_{12} A_{23}-A_{22} A_{12}\right) / \operatorname{det} \mathbf{A} \\
& P_{22}=\left(A_{11} A_{22}-A_{12}^{2}\right) / \operatorname{det} \mathbf{A} \\
& P_{23}=\left(A_{12}^{2}-A_{11} A_{23}\right) / \operatorname{det} \mathbf{A}
\end{aligned}
$$

where $\mathbf{A}=\mathbf{S}^{(\mathbf{f})}-\mathbf{S}^{(\mathbf{m})} ; \operatorname{det} \mathbf{A}=A_{11}\left(A_{22}^{2}-A_{23}^{2}\right)+2 A_{12}\left(A_{12} A_{23}-A_{22} A_{12}\right)$; and $\mathbf{S}^{(\mathbf{f})}$ and $\mathbf{S}^{(\mathbf{m})}$ are the compliance matrix of fiber and resin, respectively.

\subsection{Curing shrinkage}

During the curing process, resin will undergo substantial shrinkage (up to $5 \%$ for epoxy resin). However, because in the beginning of a typical liquid composite molding process, resin is fully uncured and behaves as viscous fluid. During the curing process, resin is heated up to a temperature usually above the glass transition temperature. A significant increase in modulus and a reduction in specific volume begin to occur. However, only a small fraction of curing shrinkage contributes to the residual stress and warpage development. Thus, in this study, the effective curing shrinkage of epoxy is assumed to be $0.6 \%$.

\subsection{Finite Element Analysis}

In this study, the deformation of composite T-stiffener structures was calculated by FEA. The validation of the FEA model is presented in an earlier study [28]. A composite T-stiffener 
part usually consists of a number of repeating stiffener sub-units, as shown in Figure 3. Each sub-unit consists of the skin and two L-frames. In this study, a four-stiffener structure is studied as an example. The relevant dimensions are: $L=400 \mathrm{~mm} ; L_{b}=200 \mathrm{~mm} ; H=150$ $\mathrm{mm}$; and $h=2 \mathrm{~mm}$. The thickness of the skin is $2 h$.

As shown in Figure 4, the skin consists of 16 laminas and the stacking sequence is [45/0/45/90/45/0/-45/0 $]_{s}$; the left and right ribs consist of 8 laminas and the stacking sequences are [-45/0/45/90/-45/0/45/0] and [45/0/-45/90/45/0/-45/0], respectively. The fiber volume fraction is $50 \%$. The noodle area is usually filled with unidirectional fibers and it is assumed that the noodle fiber volume fraction is $30 \%$.
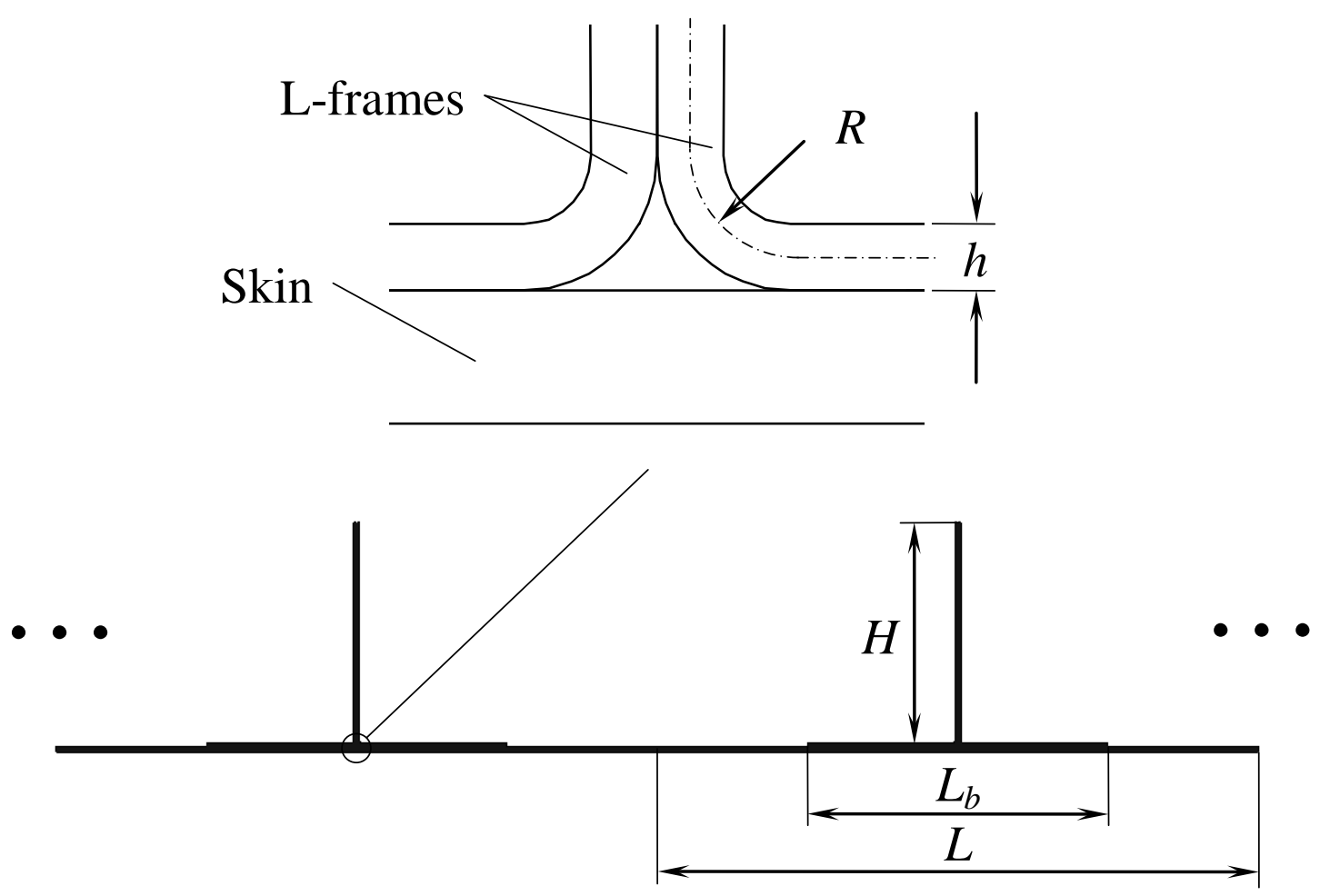

Figure 3: A composite part consisting of repeating stiffener subunits 


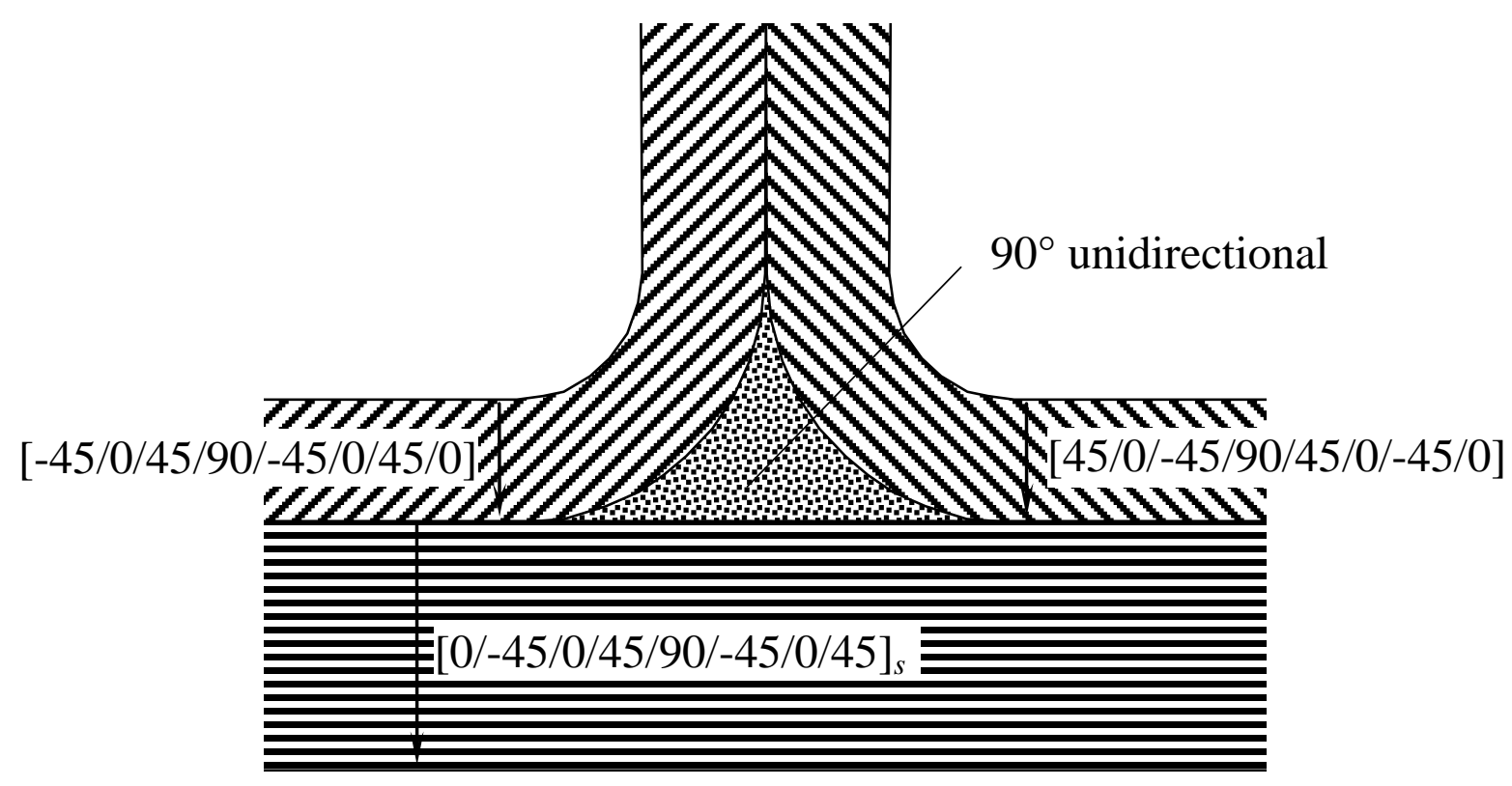

Figure 4: Stacking sequences

A commercial FEA package MSC.Marc Mentat was employed in this study. Eight-noded, isoparametric, three-dimensional brick elements are used. Because of the symmetry, only half of the structure is modeled and the part is restrained at the left-hand edge. The mesh is shown in Figure 5. 


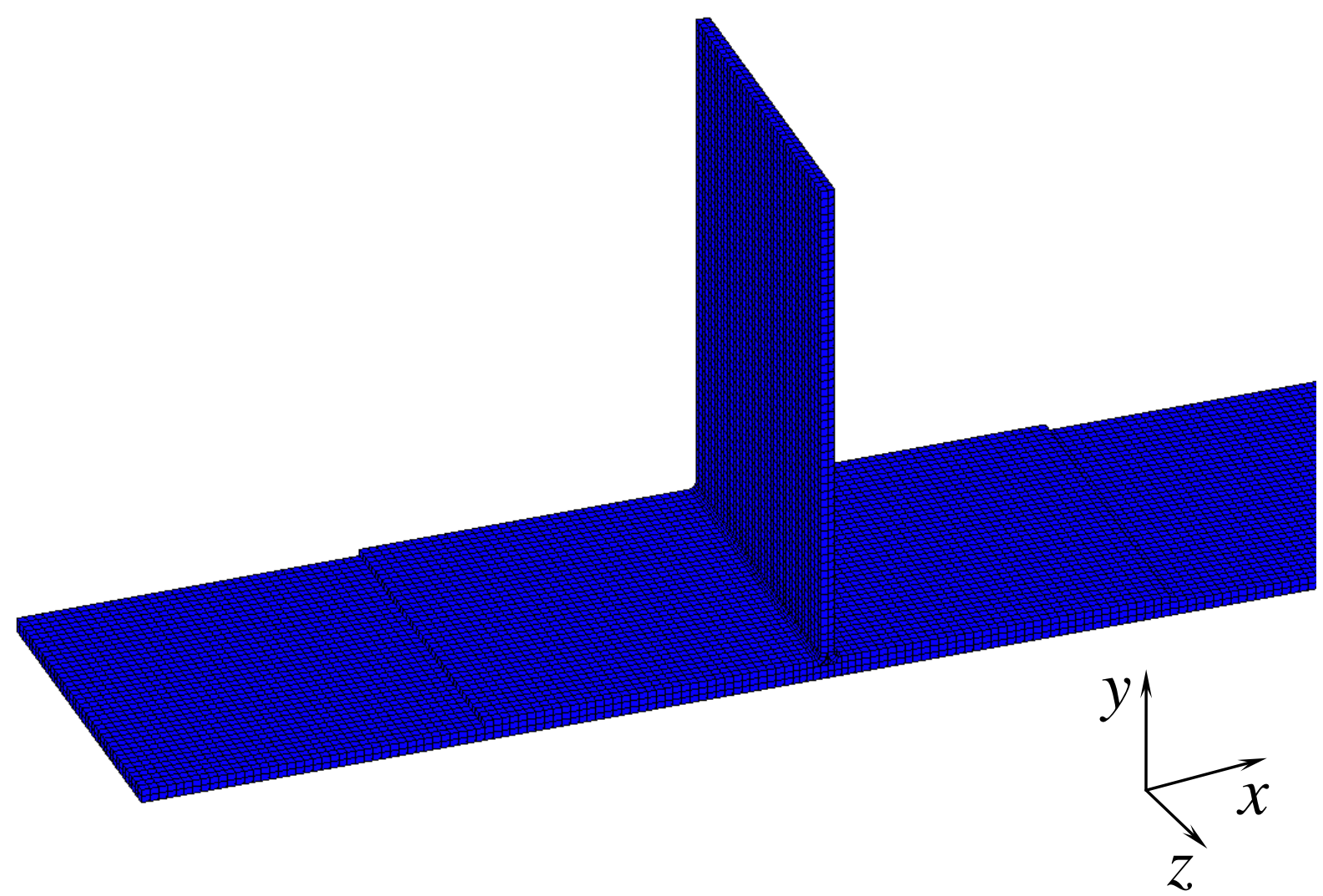

Figure 5: Mesh for FEA

In order to simulate the cooling process, the initial and final temperatures are defined to be $150^{\circ} \mathrm{C}$ and the room temperature. After computation, the resulting deformation is shown in Figure 6. The contour shows the total displacement in $\mathrm{mm}$. The deformation is like "springin”, i.e. reduction in the angle between the skin and the stiffeners. This is caused by the inplane and through-thickness CTE mismatch of the L-frames, and constraints due to the skin and the noodle areas. 


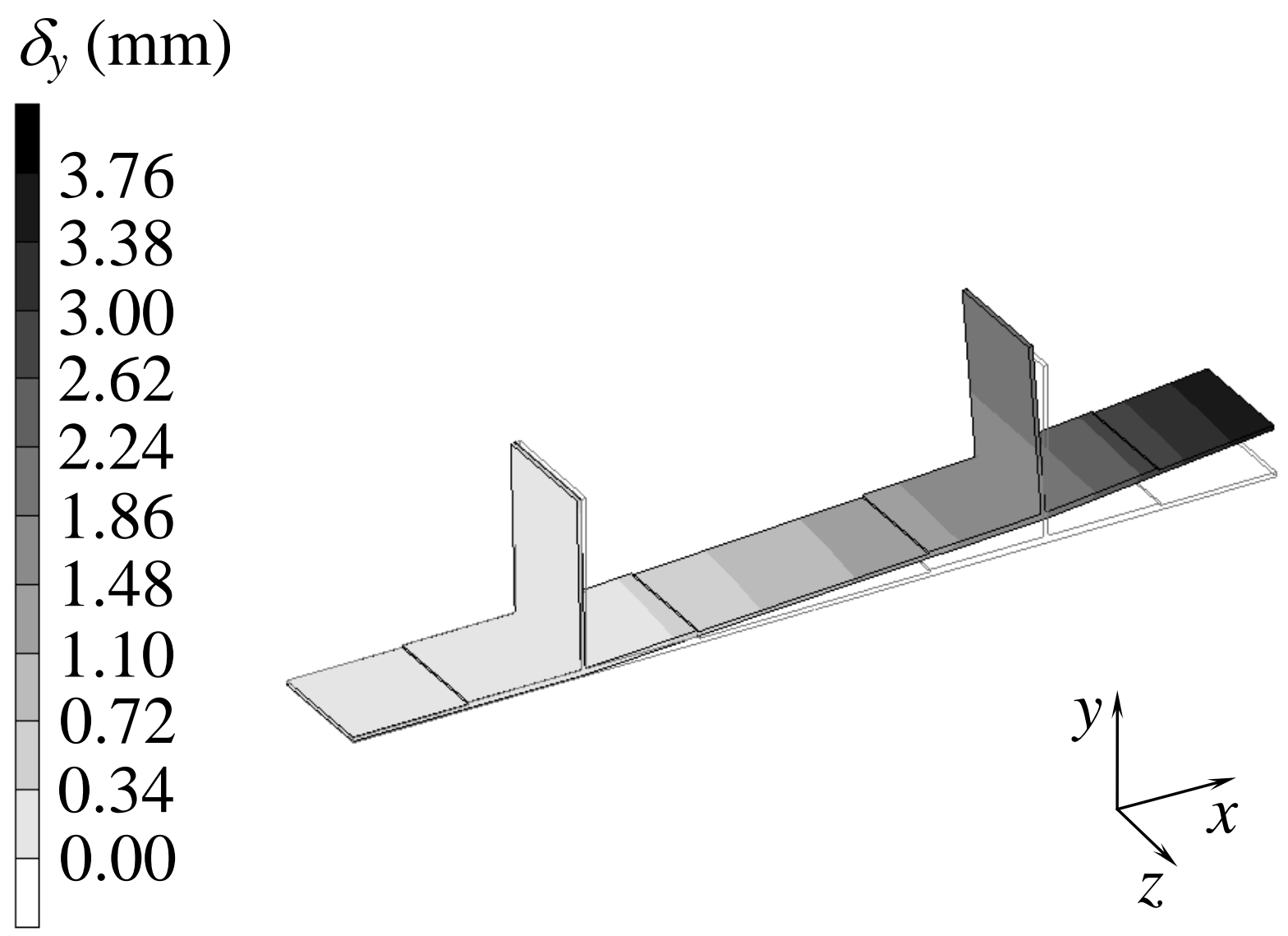



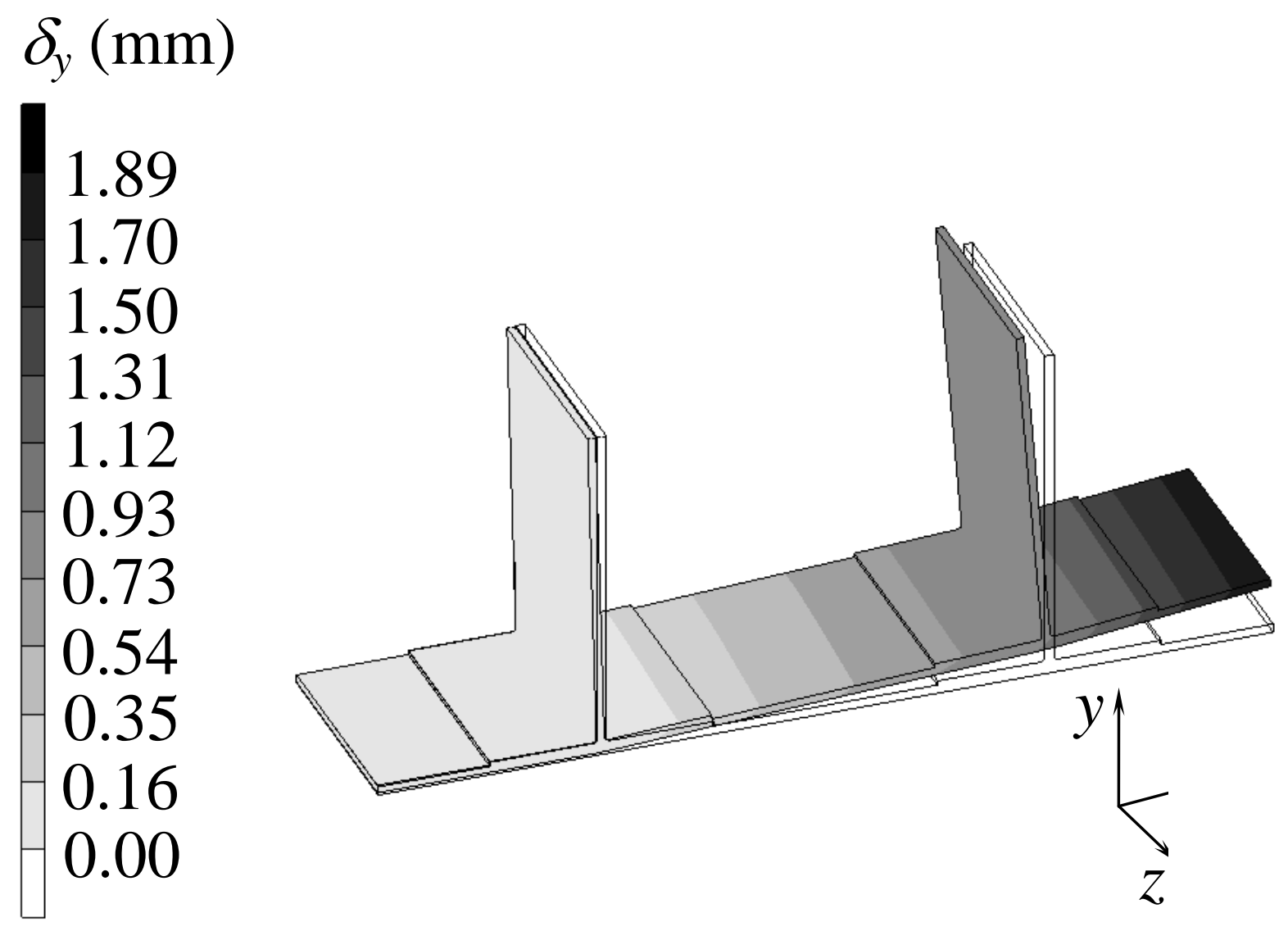

Figure 6: Deformation of the stiffener structure (mm)

\section{Deformation Characterization}

In order to characterize the deformation, the $y$-displacement of the skin is plotted versus corresponding $x$ coordinate in Figure 7 (left), from which it is shown that the $\delta_{y}-x$ curve can be divided into three regions. $\delta_{y}$ is approximately zero in the fist zone and linearly increases with $x$ in the second and third zones. Likewise, the $x$-displacements of the stiffeners are plotted versus corresponding $y$ coordinate in Figure 7 (right), from which it is shown that for both stiffeners, $\delta_{x}$ linearly decreases with $y$. 

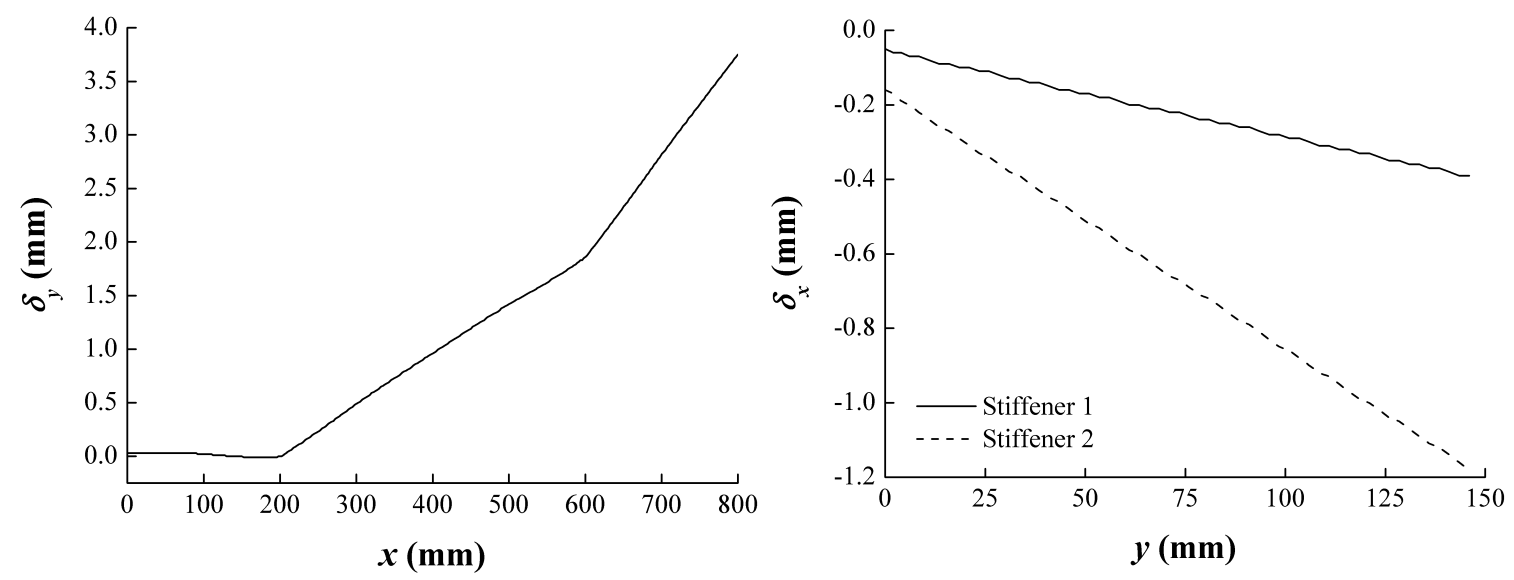

Figure 7: Left: $\delta_{y}$ of the skin vs. $x$; right: $\delta_{x}$ of the stiffeners vs. $y$

These displacements as shown in Figure 7 are given by the following equations, where the unit is mm.

Skin:

$$
\delta_{y}=\left\{\begin{array}{lr}
0 & 0 \leq x \leq 200 \\
-0.9121+4.64 \times 10^{-3} x & 200<x \leq 600 \\
-3.876+9.55 \times 10^{-3} x & 600<x \leq 800
\end{array}\right.
$$

Stiffener 1:

$$
\delta_{x}=-5.418 \times 10^{-2}-2.31 \times 10^{-3} y
$$

Stiffener 2:

$$
\delta_{x}=-0.1614-6.95 \times 10^{-3} y
$$

It can be seen Eqns. 6-8 that the displacements are linear functions of $x$ or $y$. Thus, the deformation of the stiffener structure is characterized by the angular displacements $\theta_{r 1}, \theta_{r 2}$, $\theta_{\mathrm{s} 1}$, and $\theta_{\mathrm{s} 2}$, as shown in Figure 8. 


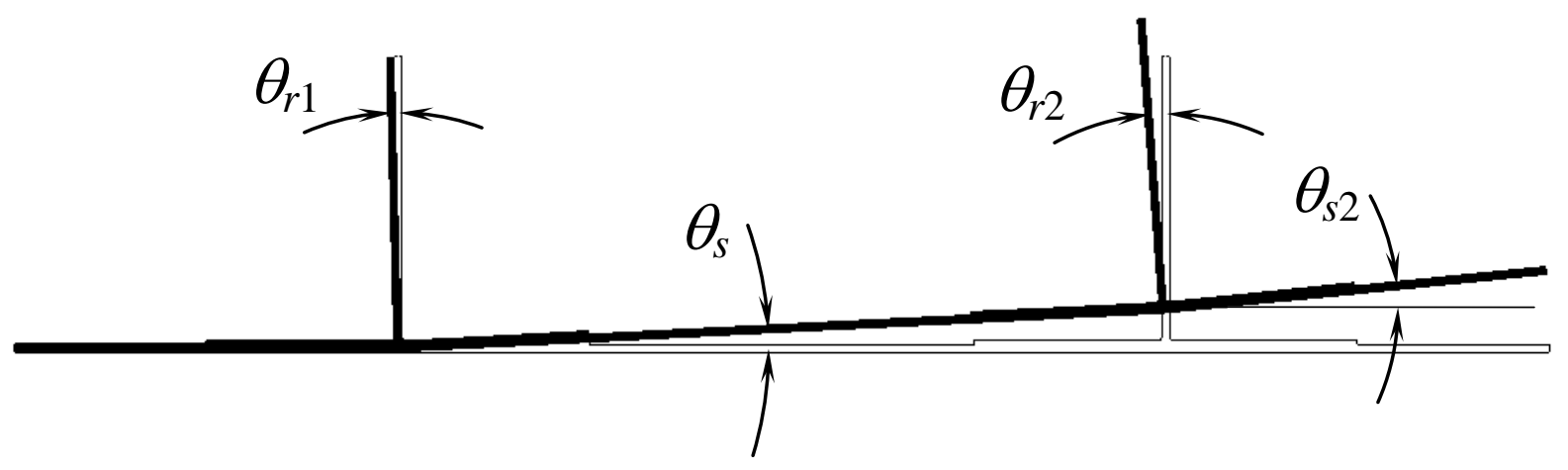

Figure 8: Angular displacements

From Eqns. 6-8 the following relationships can be derived:

$$
\begin{aligned}
& \theta_{s 1}=2 \theta_{r 1} \\
& \theta_{r 2}=\theta_{s 1}+\theta_{r 1}=3 \theta_{r 1} \\
& \theta_{s 2}=2 \theta_{s 1}
\end{aligned}
$$

For this AS4 graphite/epoxy composite T-stiffener structure, it was calculated that $\theta_{s 1}=$ $0.2763^{\circ}$. These linear relationships suggest that $\theta_{s 1}$ is independent of $L$ and $H$. This is further confirmed by another FEA case study when $L=200 \mathrm{~mm}$, which shows $\theta_{s 1}=0.2724^{\circ}$. Thus, for a T-stiffener structure, the deformation can be characterized by the spring-in of the skin $\theta_{s}$.

\section{Parametric Study}

The influence of the design parameters on the spring-in of the skin $\theta_{s}$ was investigated by Design of Experiments. For a given material system, the potential variables affecting the process-induced deformation include $L, L_{b}, H, R, h$, and $V_{f}$. The aforementioned analysis suggests that the spring-in $\theta_{s}$ is independent of $L$ and $H$. Thus, the dimensionless bond length $L_{b} / L$ is introduced. It is also shown from FEA that the spring-in is constant when the model is scaled up or down, i.e. the radius/thickness ratio is constant. Thus, a dimensionless variable 
$R / h$ is introduced. With the introduction of dimensionless variables, the design factors to be investigated are reduced to $L_{b} / L, R / h$, and $V_{f}$. For all the cases, it is assumed that $V_{f n}=30 \%$. A $2^{3}$ factorial design with center point is chosen and the levels are shown in Table 2 . Factorial designs are most efficient for experiments involving the study of the effects of two or more factors. In a factorial design, all possible combinations of the levels of the factors are investigated. Thus, it allows studying the effect of each factor on the response variable, as well as the effects of interactions between factors on the response variable [29].

Table 2: Levels of the $2^{3}$ factorial design

\begin{tabular}{ccc}
\hline Parameter & Low & High \\
\hline $\boldsymbol{L}_{b} / \mathbf{L}$ & 0.125 & 0.875 \\
$\boldsymbol{R} / \boldsymbol{h}$ & 1.5 & 5 \\
$\boldsymbol{V}_{f}$ & $40 \%$ & $60 \%$ \\
\hline
\end{tabular}

For each parameter combination, the deformation was calculated by FEA. The complete data are shown in Table 3 and they are analyzed by MINITAB ${ }^{\circledR}[30]$.

Table 3: Complete data from the $2^{3}$ factorial design with centre point

\begin{tabular}{ccccc}
\hline Order & $\boldsymbol{L}_{\boldsymbol{b}} / \boldsymbol{L}$ & $\boldsymbol{R} / \boldsymbol{h}$ & $\boldsymbol{V}_{\boldsymbol{f}}$ & $\left.\boldsymbol{\theta}_{\boldsymbol{s}} \mathbf{(}^{\circ}\right)$ \\
\hline 1 & 0.125 & 1.50 & 0.4 & 0.2930 \\
2 & 0.875 & 1.50 & 0.4 & 0.3544 \\
3 & 0.125 & 5.00 & 0.4 & 0.3911 \\
4 & 0.875 & 5.00 & 0.4 & 0.4608 \\
5 & 0.125 & 1.50 & 0.6 & 0.2262 \\
6 & 0.875 & 1.50 & 0.6 & 0.2681 \\
7 & 0.125 & 5.00 & 0.6 & 0.3112 \\
8 & 0.875 & 5.00 & 0.6 & 0.3587 \\
9 & 0.500 & 3.25 & 0.5 & 0.3196 \\
\hline
\end{tabular}

The Pareto chart for the effects is shown in Figure 9 and it can be used to compare the relative magnitude and the statistical significance of both main and interaction effects.

In Figure 9, $\mathrm{A}, \mathrm{B}$, and $\mathrm{C}$ represents the main effect of $L_{b} / L, R / h$, and $V_{f}$, respectively, which is defined as the change in response produced by a change in the level of that factor averaged 
over the levels of all the other factors. AB, BC, and AC are the two-factor interactions. For example, AB represents the interaction between $L_{b} / L$ and $R / h$, which is defined as the average difference between the effect of $R / h$ at the high level of $L_{b} / L$ and the effect of $R / h$ at the low level of $L_{b} / L$. Similarly, ABC is the three-factor interaction, which is defined as the average difference between the $\mathrm{AB}$ interactions for the two different levels of $\mathrm{C}$.

These effects are plotted in decreasing order of the absolute value of the standardized effects and a reference line is drawn on the chart. Any effect that extends past this reference line is significant. In this case, the $\alpha$-level was set to be 0.10 . It can be seen that all three factors $L_{b} / L, R / h$, and $V_{f}$ are significant. In addition, the most significant factor is $R / h$ because it extends the farthest.

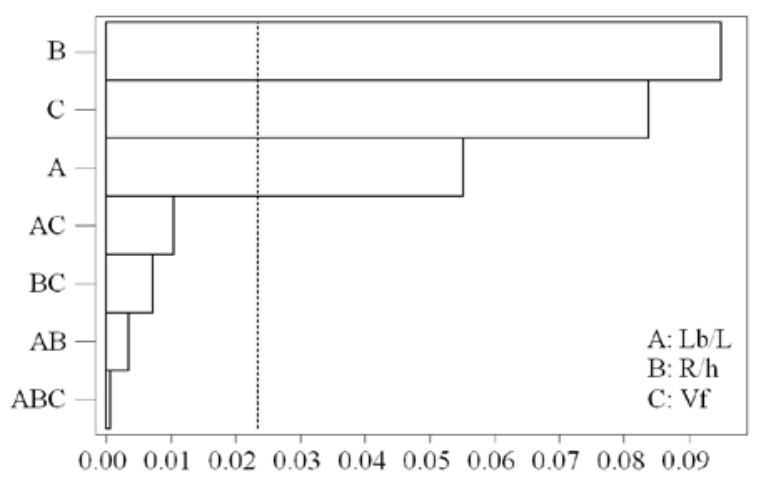

Figure 9: Pareto chart for the effects

The main effects plot is shown in Figure 10 for determining which factors influence the response and comparing the relative strength of the effects. In Figure 10, the response means for each factor level are plotted and the points for each factor are connected. A reference line is drawn at the overall (grand) mean. It is seen that $\theta_{s}$ increases with $L_{b} / L$ and $R / h$, and decreases $V_{f}$. It is also shown from Figure 10 that the center point deviates from the straight line, which indicates the existence of non-linear relationships. This needs further 
investigations.

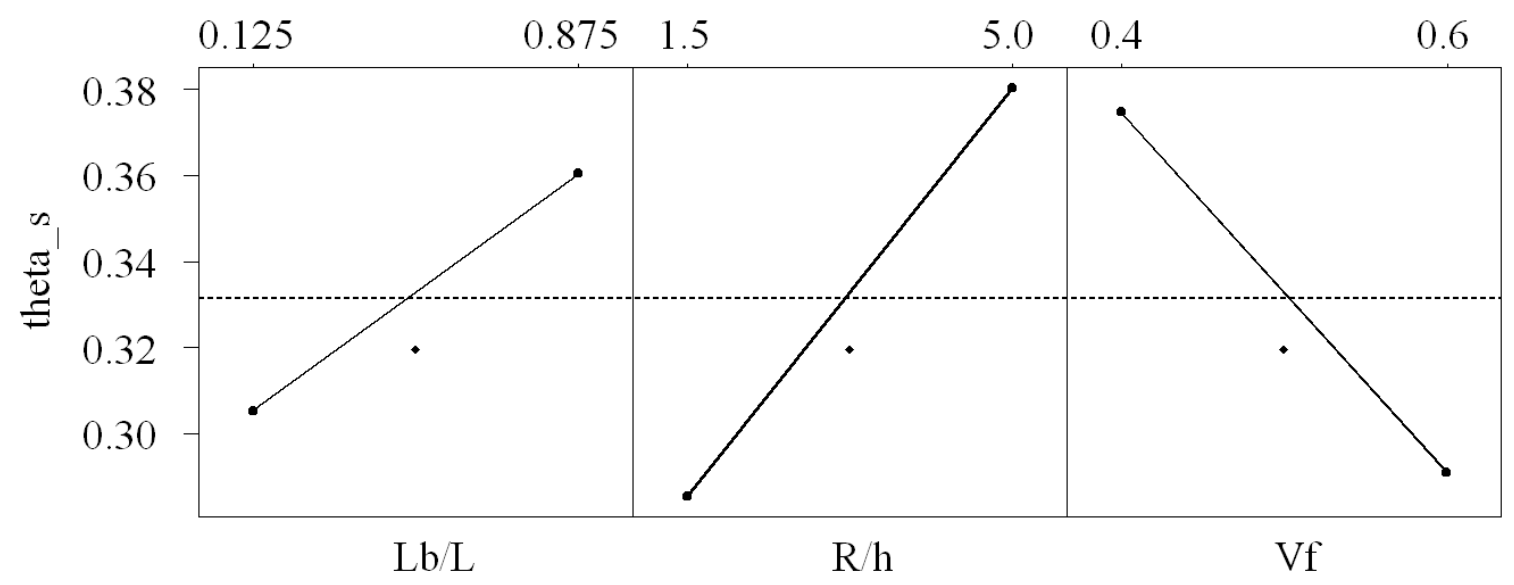

Figure 10: Main effects plot

\section{Conclusions}

A study on the process-induced deformation of composite T-stiffener structures is presented in this paper. The deformation was calculated numerically by Finite Element Analysis (FEA), and the resulting displacements show that the deformation can be represented by a single angular displacement: the spring-in of the skin. A parametric study was conducted by Design of Experiments (DOE) and FEA to investigate the influence of design parameters on the spring-in of the skin. It is shown that the spring-in of the skin increases with the radius and the bonding length, and decreases with the fiber volume fraction.

\section{Acknowledgement}

The author acknowledges the support from the Curtin Research Fellowship.

\section{References}

1. (2002) Military Handbook - MIL-HDBK-17-3F: Composite Materials Handbook, 
Volume 3 - Polymer Matrix Composites Materials Usage, Design, and Analysis, U.S. Department of Defense.

2. Cairns, D. S., Samborsky, D. D., Haugen, D. J. and Mandell, J. F. (1998) Fracture of skin/stiffener intersections in composite wind turbine structures. 1998 ASME Wind Energy Symposium and 36th AIAA Aerospace Sciences Meeting and Exhibit. Reno, NV, ASME International.

3. Hahn, H. T. and Pagano, N. J. (1975) Curing stress in composite laminates. Journal of Composite Materials, 9: p. 91-105.

4. Radford, D. W. and Diefendorf, R. J. (1993) Shape instabilities in composite resulting from laminate anisotropy. Journal of Reinforced Plastics and Composites, 12(1): p. 58-75.

5. Huang, C. K. and Yang, S. Y. (1997) Warping in advanced composite tools with varying angles and radii. Composites Part A, 28(9-10): p. 891-893.

6. Kollar, L. P. (1994) Approximate analysis of the temperature induced stresses and deformations of composite shells. Journal of Composite Materials, 28(5): p. 392-414.

7. Jain, L. K., Lutton, B. G., Mai, Y. W. and Paton, R. (1997) Stresses and deformations induced during manufacturing. Part II: a study of the spring-in phenomenon. Journal of Composite Materials, 31(7): p. 696-719.

8. Jain, L. K. and Mai, Y. W. (1997) Stresses and deformations induced during manufacturing. Part I: theoretical analysis of composite cylinders and shells. Journal of Composite Materials, 31(7): p. 673-695.

9. Wang, J., Kelly, D. and Hillier, W. (2000) Finite element analysis of temperature induced stresses and deformations of polymer composite components. Journal of Composite Materials, 34(17): p. 1456-1471.

10. Ding, Y., Chiu, W. K. and Liu, X. L. (2001) Anisotropy related 'spring-in' of angled composite shells. Polymers \& Polymer Composites, 9(6): p. 393-401.

11. Clifford, S., Jansson, N., Yu, W., Michaud, V. and Manson, J.-A. (2006) Thermoviscoelastic anisotropic analysis of process induced residual stresses and dimensional stability in real polymer matrix composite components. Composites Part A, 37(4): p. 538-545.

12. Weitsman, Y. (1979) Residual thermal stresses due to cool-down of epoxy-resin composites. Journal of Applied Mechanics, 46(3): p. 563-567.

13. Wang, T. M., Daniel, I. M. and Gotro, J. T. (1992) Thermoviscoelastic analysis of residual stresses and warpage in composite laminates. Journal of Composite Materials, 26(6): p. 883-899.

14. White, S. R. and Hahn, H. T. (1992) Process modeling of composite materials: residual stress development during cure. Part I: model formulation. Journal of Composite Materials, 26(16): p. 2402-2422.

15. White, S. R. and Hahn, H. T. (1992) Process modeling of composite materials: residual stress development during cure. Part II: experimental validation. Journal of Composite Materials, 26(16): p. 2423-2454.

16. Li, M. C., Wu, J. J., Loos, A. C. and Morton, J. (1997) A plane-strain finite element model for process-induced residual stresses in a graphite/PEEK composite. Journal of Composite Materials, 31(3): p. 212-243.

17. Wiersma, H. W., Peeters, L. J. B. and Akkerman, R. (1998) Prediction of springforward in continuous-fiber/polymer L-shaped parts. Composites Part A, 29(11): p. 1333-1342.

18. Fernlund, G., Osooly, A., Poursartip, A., Vaziri, R., Courdji, R., Nelson, K., George, P., Hendrickson, L. and Griffith, J. (2003) Finite element based prediction of processinduced deformation of autoclaved composite structures using 2D process analysis 
and 3D structural analysis. Composite Structures, 62(2): p. 223-234.

19. Johnston, A., Vaziri, R. and Poursartip, A. (2001) A plane strain model for processinduced deformation of laminated composite structures. Journal of Composite Materials, 35(16): p. 1435-1469.

20. Zhu, Q., Geubelle, P. H., Li, M. and Tucker, C. L., III (2001) Dimensional accuracy of thermoset composites: simulation of process-induced residual stresses. Journal of Composite Materials, 35(2): p. 2171-2205.

21. Sadhir, R. M. L. a. R. K. (1992) Shrinkage in conventional monomers during polymerization. IN SADHIR, R. K. \& LUCK, R. M. (Eds.) Expanding Monomers. Boca Raton, FL, CRC Press.

22. Genidy, M. S., Madhukar, M. S. and Russell, J. D. (2000) A new method to reduce cure-induced stresses in thermoset polymer composites part II: closed loop feedback control system. Journal of Composite Materials, 34(22): p. 1905-1925.

23. Madhukar, M. S., Genidy, M. S. and Russell, J. D. (2000) A new method to reduce cure-induced stresses in thermoset polymer composites Part I: test method. Journal of Composite Materials, 34(22): p. 1882-1904.

24. Russell, J. D., Madhukar, M. S., Genidy, M. S. and Lee, A. Y. (2000) A new method to reduce cure-induced stresses in thermoset polymer composites part III: correlating stress history to viscosity degree of cure and cure shrinkage. Journal of Composite Materials, 34(22): p. 1926-1947.

25. Chou, T.-W. (1992) Microstructural Design of Fiber Composites, Cambridge, U.K., Cambridge University Press.

26. Adams, D. F. (1989) Properties characterization - mechanical/physical/hygrothermal properties test methods. IN LEE, S. M. (Ed.) Reference Book for Composites Technology Lancaster, PA, Technomic Pub Co.

27. Bowles, D. E. and Tompkins, S. S. (1989) Prediction of coefficients of thermal expansion for unidirectional composites. Journal of Composite Materials, 23(4): p. 370-388.

28. Dong, C., Zhang, C., Liang, Z. Y. and Wang, B. (2004) Dimension variation prediction for composites with finite element analysis and regression modeling. Composites Part A, 35(6): p. 735-746.

29. Montgomery, D. C. (2000) Design and Analysis of Experiments, 5th Edition, New York, John Wiley \& Sons, Inc.

30. www.minitab.com. 